\title{
Solar Powered E-Military
}

\author{
Karthikeyan $\mathbf{N}^{1}$, Murugesan K.S $\mathbf{2}^{2}$, Senthil Kumar $\mathbf{P}^{\mathbf{3}}$, Pooranachandran $\mathrm{S}^{\mathbf{4}}$ \\ Assistant Professor (Sr.Gr), ECE, Velalar College of Engineering and Technology, Erode, India ${ }^{1,2,3,4}$
}

\begin{abstract}
Soldiers are the Army's most important resource. Soldiers play a vital role to protect one's country. The term soldiers include service men and women from the Army, Air force, Navy and Marines. They will always be the one responsible for taking and holding the duty in extreme weather conditions throughout the year. While providing security to the nation, they may face troubles in extreme hot/cold weather conditions. Both very cold and very hot temperatures could be dangerous to health. Excessive exposure to heat referred to as heat stress and excessive exposure to cold referred to as cold stress. In a very hot environment, the most serious concern is heat stroke. At very cold temperature, the serious concern is the risk of hypothermia or dangerous overcooling of the body. In this project we are going to design an EUniform which gives better protection to the soldiers who are working in extreme weather conditions. This uniform will make the soldiers to work in any kind of environment. And we are going to design a refrigerator cum oven in this project. By harnessing solar energy, this refrigerator cum oven is able to keep perishable goods and dairy cool in hot climates and warm in cold climates. It is also used to keep much needed vaccines at their appropriate temperature to avoid spoilage. The portable devices can be constructed with simple components and are perfect for areas of the developing world where electricity is unreliable or non-existent.
\end{abstract}

Keywords: Microcontroller, Solar panel, Rechargeable battery, Peltier plate.

\section{INTRODUCTION}

Warriors are the Army's most imperative asset. Warriors assume an essential part to ensure one's nation. The term warriors incorporate administration men and ladies from the Army, Air force, Navy and Marine. While giving security to the country, they might confront inconveniences in hot/frosty climate conditions. Both exceptionally hot and icy temperatures could be unsafe to well being. This venture is a solution for this circumstance. In this venture an E-Uniform is planned which gives better security to the officers who are working in great climate conditions. In this undertaking we are going to plan an E-Uniform which gives better assurance to the fighters who are working in amazing weather conditions. This Uniform will make the trooper to work in any sort of environment.

Here we are utilizing Solar Panels to control up the inside hardware of the E-uniform. A 12 V DC lead corrosive rechargeable battery is utilized for putting away the vitality. We are utilizing routine battery charging unit additionally to give supply to the hardware. AT89S52 miniaturized scale controller is the heart of the circuit as it controls every one of the capacities. A voltage sampler is interfaced with the framework utilizing ADC 0808 to get the voltage produced from battery as a showcase on a 16X2 LCD. The undertaking is worked in two modes summer mode and winter mode. By selecting the method of operation, we are working the H-Bridge IC such that it can drive body radiator/cooler. The warmer/cooler thus will help us to give chilling or warming impact inside the uniform which helps the officer to stand to any sort of outer environment and he can work proficiently without warmth stress or frosty anxiety. A $12 \mathrm{~V} \mathrm{DC}$ lead corrosive rechargeable battery is utilized for putting away the vitality.

We are utilizing traditional battery charging unit likewise to give supply to the hardware. This Conventional force source utilizes managed 5V, 500mA power supply. 7805 three terminal voltage controller is utilized for voltage regulation. Span sort full wave rectifier is utilized to amend the air conditioner yield of optional of $230 / 12 \mathrm{~V}$ stage down transformer. The same circuit is used for refrigerator cum oven system. This system consists of embedded devices, Solar panel, charger, battery, display, analog to digital Converter (ADC), Peltier module. Peltier is a Module which generates a voltage when there is a different temperature on each side. Conversely, when a voltage is applied to it, it creates a temperature difference.

At the atomic scale, an applied temperature gradient causes charge carriers in the material to diffuse from the hot side to the old side. So the Peltier module can cool and heat the chamber. Temperature related inconveniences such as heat stroke, heat rash, frostbite, hypothermia and others, have been a persistent problem for people throughout history. Some of these conditions, when left unchecked, have led to unfortunate deaths. What is even more common is the dissatisfaction that 
people have with the weather at various points of the year. People often complain that it is either too hot or too cold. The current technological solutions made to keep people thermally comfortable such as air conditioning and heating units have come a long way and have been successful in helping people obtain comfort in their dwellings (e.g. home or car), but are not personal mobility solutions.

What if one has to be out in the weather? The addition or subtraction of layers with coats and jackets or beach wear, are popular solutions to that problem, but do not always yield upmost satisfaction, for layers become cold over time and sunburn is a serious problem. This is why a heating/cooling suit is a very beneficial product for the masses. Such a suit allows the user to control and monitor the internal temperature of the suit from high temperatures to low temperatures, depending on the season. Creating the most comfortable thermal environment for the user within an enclosed space of small proximity while providing comfort, practicality and mobility is the objective of this suit. With the use of the thermoelectric effect, microcontroller technology and a bit of ingenuity, this suit can be realized.

\section{BLOCK DIAGRAM}

Block diagram consisting of solar panel and lead acid battery and voltage regulator and main fridge which is shown in above figure 1 .

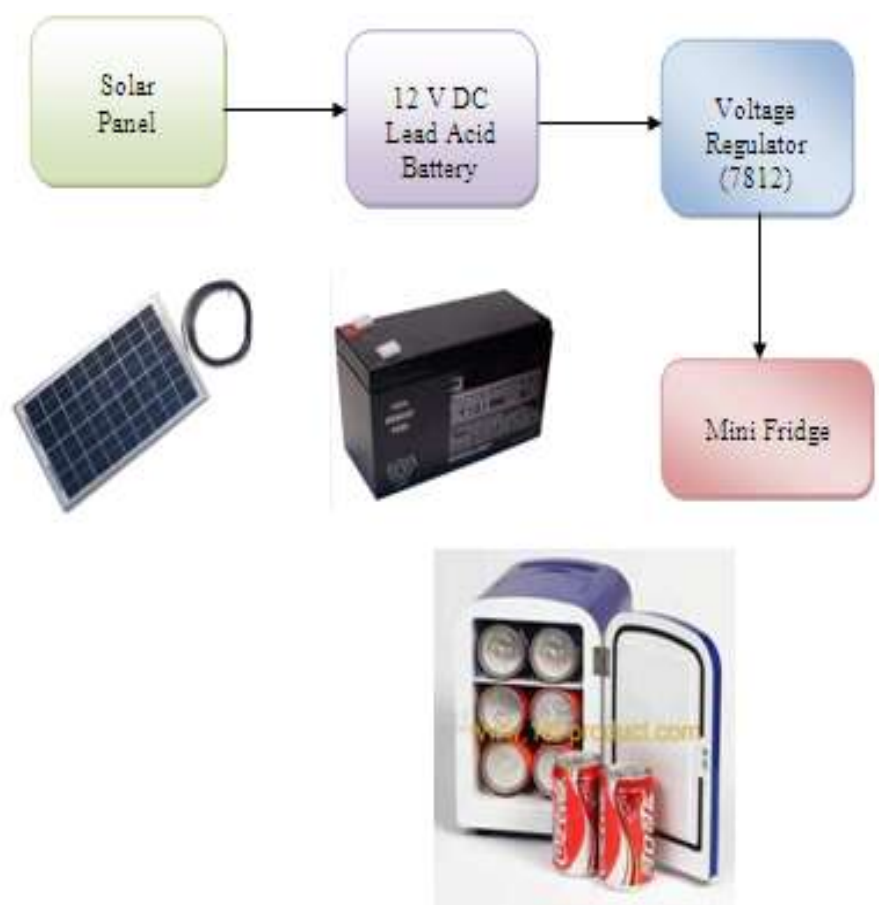

Fig 1. Refrigerator cum oven

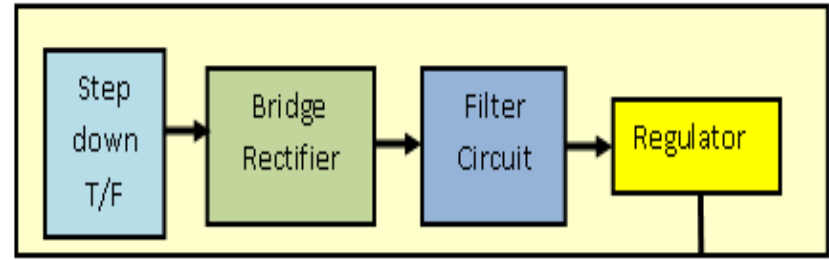

Conventional Battery Charger Unit

Fig 2. supply unit for refrigerator cum oven 
International Journal of Advanced Research in Computer and Communication Engineering ISO 3297:2007 Certified

Vol. 6, Issue 4, April 2017

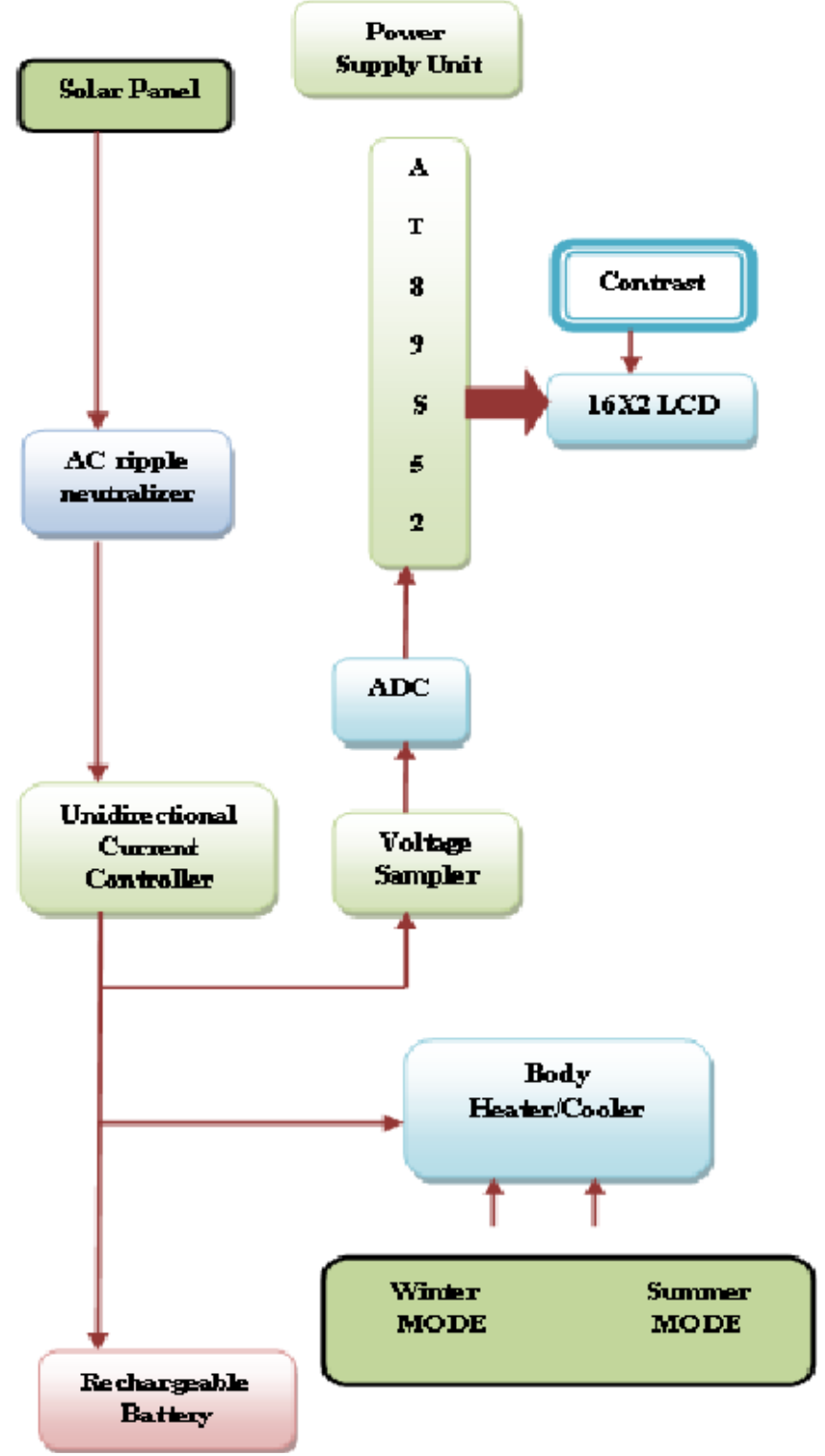

Fig 3. E-Uniform

\section{A.MICROCONTROLLER}

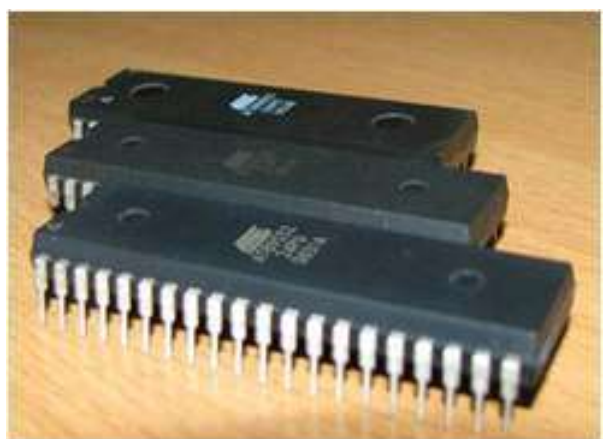

Fig. 4 AT89S52 Microcontroller 
Microcontroller is expected to persistently sense climate the dirt is dry or wet. What's more, reaction is given to on or off the water supply. In the meantime the framework will alarm the client by sending SMS through GSM module. The AT89S52 is an elite CMOS 8-bit microcontroller, low-power, with 8K bytes of EPROM. These are elements of AT89S52 microcontroller: 256 bytes of RAM, $8 \mathrm{~K}$ bytes of Flash, three 16-bit clock/counters, 32 info/yield pines , two information pointers, Watchdog clock. six hinder of two level structural planning, serial port, oscillator. The AT 89C52 is intense MC which gives an adaptable and reasonable result to numerous inserted framework applications.

\section{B.SOLAR PANEL}

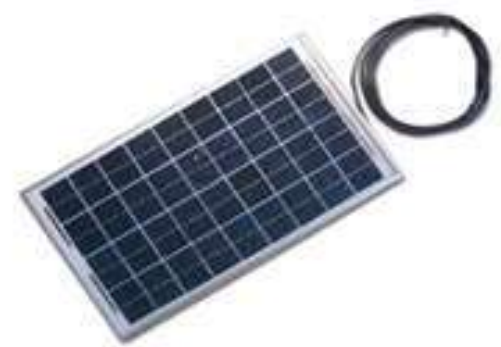

Fig. 5 Solar Panel

Recently included component for our undertaking is - Solar Panel. As we were confronting issue for consistently release of $12 \mathrm{v}$ battery utilized at recorded. We at long last chose to go for sun oriented board renewable vitality source. It changes over light vitality from the sun into $12 \mathrm{Volt}$ DC power. Gradually charges our $12 \mathrm{~V}$ battery. It likewise keeps up a charge and amplify battery's life. It ensures battery through long stockpiling periods. This sunlight based board charger has no moving parts that could destroy after some time.

\section{C.ADC}

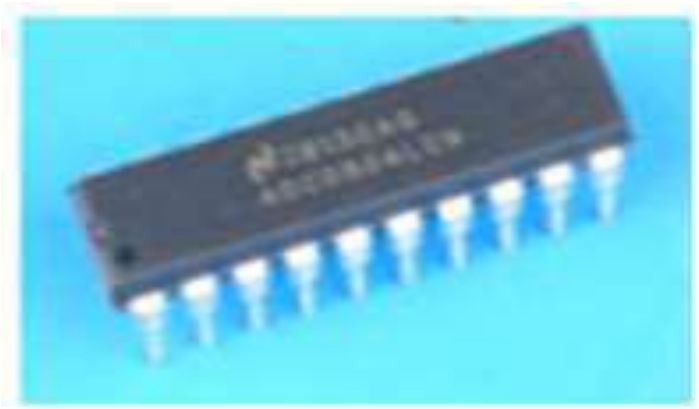

Fig. 6 Analog To Digital Converter

ADC is utilized to change over the simple qualities into advanced qualities. We are utilizing ADC 0808 on the grounds that it has higher determination than other ADC.

\section{D.LCD}

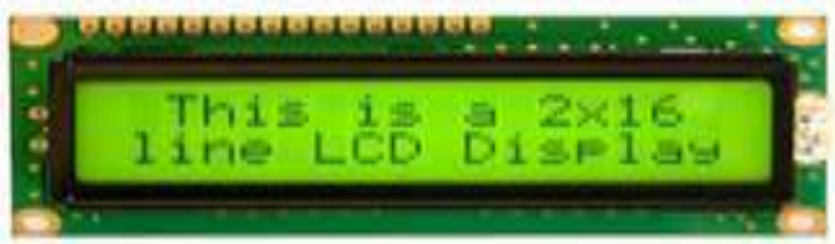

Fig. 7 LCD Panel

LCD stands for liquid crystal display. LCD used is 16 by 2. It contains the 16 pin. 8 pin is used for data communication, read, write, enable, Brightness control and 4 pins for power supply. It is used to display data. 
FEATURES OF LCD

$>16$ Characters $\times 2$ Lines

$>5 \times 7$ Dot Matrix Character + Cursor

$>$ 4-bit or 8-bit MPU Interface

$>$ Standard Type

$>$ Works with almost any Microcontroller

$>$ Great Value Pricing

$>$ Maximum input voltage: 5.3VDC

$>$ Operating input voltage: 5VDC

8-bit interface data bus

$>$ Character font size: $0.125 " \mathrm{~W}$ x $0.200 " \mathrm{H}$

\section{A.BATTERY}

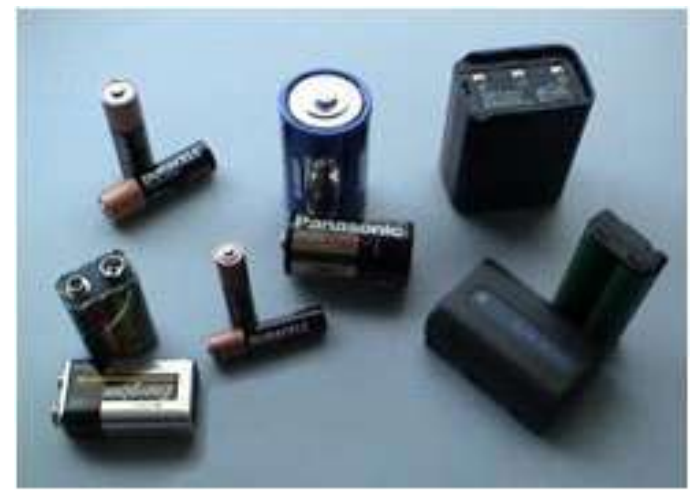

Fig. 8 Batteries

Battery (power), a variety of electrochemical cells for power stockpiling, either exclusively Connected or independently connected and housed in a solitary unit. An electrical battery is a mix of one or more electrochemical cells, used to change over put away concoction vitality into electrical vitality. Batteries might be utilized once and tossed, or energized for quite a long time as in standby force applications. Small cells are utilized to power gadgets, for example, portable amplifiers and wristwatches; bigger batteries give standby energy to phone trades or PC server farms.

\section{AC RIPPLE NUTRALIZER}

The most well-known significance of swell in electrical science is the little undesirable leftover occasional variety of the immediate current (dc) yield of a force supply which has been gotten from a substituting current (air conditioning) source. This swell is because of inadequate concealment of the substituting waveform inside of the force supply.

\section{VOLTAGE SAMPLER}

Test and hold circuits is utilized to test a simple sign and to store its worth for some period of time (for computerized code change). It is intensely utilized as a part of information converters. Test and-hold are likewise alluded to as track-and-hold circuits.

\section{CONTROL SUPPLY}

The 230A.C information is given to rectifier circuit and Output get from the rectifier is a throbbing D.C voltage. The yield from the rectifier is given to a channel circuit to channel A.C parts present steady later than correction. Presently, this voltage encouraged to voltage controller to unadulterated steady D.C voltage get.

\section{PELTIER STRUCTURE}

A typical thermoelectric module consists of an array of Bismuth Telluride semiconductor pellets that have been "doped" so that one type of charge carrier- either positive or negative- carries the majority of current. The pairs of P/N pellets are configured so that they are connected electrically in series, but thermally in parallel. Metalized ceramic substrates provide the platform for the pellets and the small conductive tabs that connect them. 


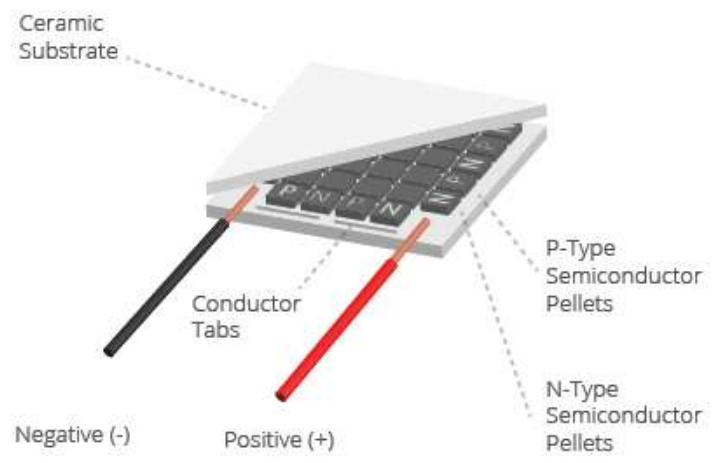

Fig. 9 Construction

When DC voltage is applied to the module, the positive and negative charge carriers in the pellet array absorb heat energy from one substrate surface and release it to the substrate at the opposite side. The surface where heat energy is absorbed becomes cold; the opposite surface where heat energy is released, becomes hot. Reversing the polarity will result in reversed hot and cold sides.

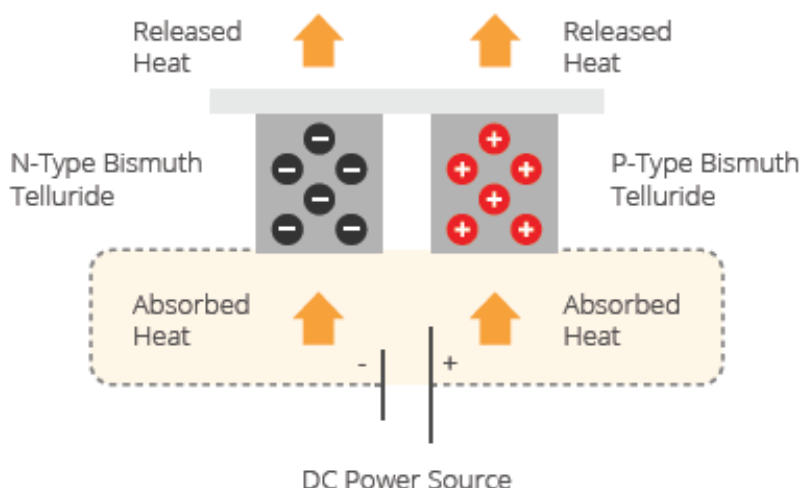

Fig. 10 Theory

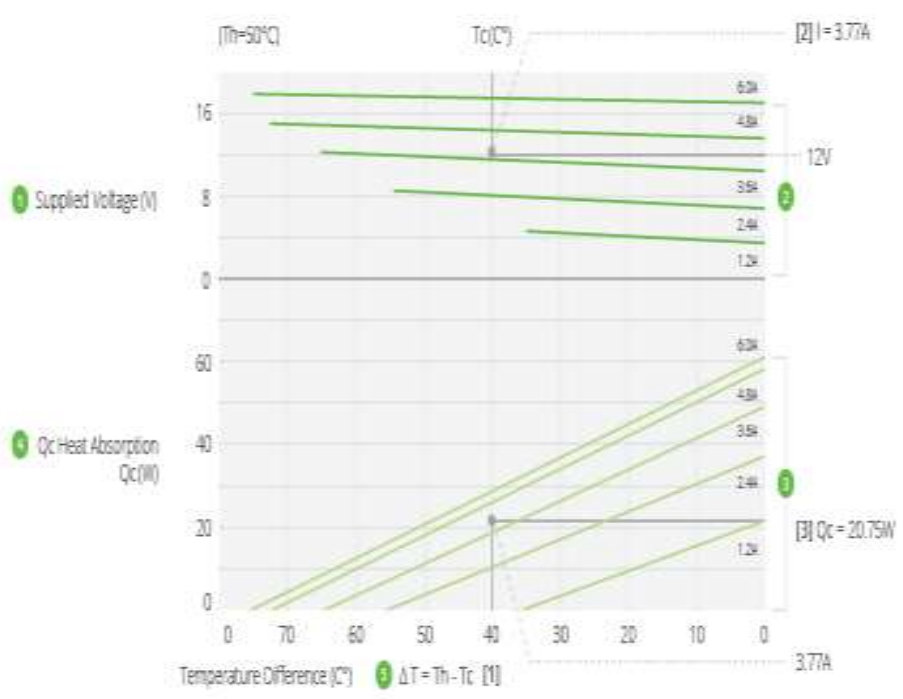

Fig. 11 Function Diagram 
1) Potential difference across the Peltier Module (V).

2) The connection between $\Delta \mathrm{T}\left({ }^{\circ} \mathrm{C}\right)$ for each supplied current and voltage $(\mathrm{V})$.

3) The connection between $\Delta \mathrm{T}\left({ }^{\circ} \mathrm{C}\right)$ for each supplied current and heat absorption (W).

4) Heat absorption of the Peltier Module (W).

5) The temperature difference $(\Delta \mathrm{T})$ shows the difference between the hot side and cool side of the peltier module and the electrodes. It is not the difference between the cool side and the background temperature.

\section{SOFTWARE DESCRIPTION}

This undertaking is executed utilizing taking after software's:

$>$ Embedded $\mathrm{C}$

$>$ Keil

$>$ Proload

$>$ Fit and forget system

ADVANTAGES

$>$ Reliable

$>$ Compact size

$>$ Affordable prize (Low cost)

$>$ Low Maintenance

\section{APPLICATION}

$>$ Used in military applications.

$>$ This uniform can be used for all the climatic applications.

$>$ Soldiers can work in extreme climatic applications.

$>$ Used to store medicines and other beverages

$>$ Used as a refrigerator at home applications

\section{RESULT}

This task "Sunlight based E-Uniform for officers who work at compelling high temperature or great low temperature and refrigerator cum oven." is effectively tried and actualized which is the best sparing, moderate vitality answer for basic individuals.

\section{CONCLUSION}

Officers are one of the imperative components in a nation. Since they are the strengths who secure our nation day and night living behind rest and rest. In this manner it is our obligation to ensure them. Same is the centrality of this undertaking. So here outline an E Uniform which gives better insurance to the warriors who are working in compelling climate conditions. This venture is worked in two modes summer mode and winter mode. In the event that the climate condition is excessively hot then the cooling framework will worked and in the event that it is excessively cool then the warming framework will worked. In the event that this framework might come up short GPS will discover the position of troopers and send messages by means of GSM to the control station. This venture has a huge part in our everyday life .Also it can be utilized as a part of different floods of industrial applications.

\section{REFERENCES}

[1] Shun Chen, Jun Zuo and Dan Xie "Design of solar power semiconductor refrigerator" in the proceedings of the 8th World Congress on Intelligent Control and Automation July 6-9 2010, Jinan, China.

[2] Haidar. S, Isaac. I "Thermo-electric Cooling Using Peltier Cells in Cascade," (2004).

[3] Sanjaykumar A Borikar and Uday S Wankhede "Experimental analysis of solar refrigeration system" in the proceedings of the International Conference at Purdue, July 14-17, 2008.

[4] Chemperi and Kannur "E-UNIFORM FOR SOLDIER'S WHO WORK AT EXTREMETEMPERATURE REGIONS" Vimal Jyothi Engineering College, Kerala, India. ISSN 2091-2730

[5] Mazidi and Mazidi “The 8051 Microcontroller and Embedded Systems Using Assembly and C”, ISBN 8131710262, 9788131710265 